\title{
The ethics of natural history documentaries
}

\author{
Simone Pollo ${ }^{\mathrm{a}, *}$, Mariuccia Graziano ${ }^{\mathrm{b}, 1}$, Cristina Giacoma ${ }^{\mathrm{b}, 1}$ \\ a Dipartimento di Studi filosofici ed epistemologici, Università di Roma 'La Sapienza' \\ ${ }^{\mathrm{b}}$ Dipartimento di Biologia animale e dell'uomo, Università di Torino
}

\section{A R T I C L E I N F O}

\section{Article history:}

Received 28 October 2008

Initial acceptance 8 December 2008

Final acceptance 23 January 2009

Published online 20 March 2009

MS. number: 08-00701

\section{Keywords:}

animal welfare

anthropomorphism

ethics

film

guidelines

legislation

natural history documentary

photography

Animal behaviour has been a favourite subject for film-makers and photographers since the invention of the first cameras (Tosi 1984; Bousè 2000). In the second half of the 20th century, the general public's interest in documentaries and natural history reportage has grown enormously. Nowadays, the depiction of animal life is an industry and several different professions are involved in it. Producing a documentary depicting animals is one of the many interactions between humans and nonhuman-animals (from now on 'animals') and, like all the other human-animal relationships, it raises ethical issues. Nowadays, the moral aspects of many of these relations are being analysed and debated publicly. Such analyses and debates are filling the gap between theoretical research on the moral status of animals and the daily practice of professionals working with animals (Fraser 1999). None the less, it seems that little attention has been paid to it and there are few analytical discussions on ethical issues in the making of natural history documentaries. Here we try to offer a bird's-eye survey of

\footnotetext{
* Correspondence: S. Pollo, Dipartimento di Studi filosofici ed epistemologici, Università di Roma 'La Sapienza', Via Carlo Fea 2, 00161 Rome, Italy.

E-mail address: simone.pollo@uniroma1.it (S. Pollo).

1 M. Graziano and C. Giacoma are at the Dipartimento di Biologia animale e dell'uomo, Universitá di Torino, Via Accademia Albertina 13, 10123 Turin, Italy.
}

such issues. Our aim is to encourage debate on the moral questions of the production of natural history documentaries.

As a start, it is useful to identify our topic more precisely by pointing out what we mean by 'natural history documentary'. A 'natural history documentary' is a photo or audio-video reportage depicting live animals and aimed at showing their habits and behaviours for educational and entertainment purposes. Documentaries often depict animal life by mixing photos and/or videos with commentaries and opinions from experts. All these elements are organized in a narrative form. Therefore, our definition does not include the raw photo/audio/video sampling that is usually collected during behavioural research. Of course, the production of this kind of sampling also raises ethical issues, but our aim is to focus directly on natural history documentaries as a product of the entertainment industry and of other ways of communicating science to the general public.

Some of the ethical issues of the making of documentaries are similar to those raised by other kinds of human-animal relations. Some problems are akin to those entailed in behavioural research on animals (i.e. filming animals for pure research purposes) and in the use of animals in sport and entertainment (i.e. using animals in races; movie making with animal actors). None the less, the production of documentaries presents its own problems and it should be considered a separate theme for ethical analysis. In this 
paper we highlight the topics that are specific to the making of natural history documentaries.

First, we highlight which human interests should be particularly taken into account and how natural history documentaries could threaten or benefit them. Then, we examine which animal interests are affected by the making of documentaries and how. Finally, we conclude with some tentative proposals to balance and protect human and animal interests in the making of documentaries. To reach this goal, we start with the premise that a morally acceptable balance of all the interests involved should yield reasonable lines of conduct. Lines of conduct will be reasonable if they take into account all the different aspects of the practice: ethical, legal, scientific, technical and so on.

\section{The Interests of Humans as Viewers}

In developed countries, natural history documentaries are the most important source of information about animal life. Although naturalistic tourism seems to be increasing, for the great majority of people in the affluent societies real-life interactions with animals are mostly limited to pets and to the species living in urbanized environments. Therefore, for lay people not trained in biological science, documentaries are likely to be the main source of knowledge about many species (such as animals living outside western countries or living inside these countries in the wild). From this fact, it can be argued that many humans have an interest in the production of natural history documentaries. They are a source of knowledge and entertainment and, like other kinds of knowledge and amusement, can promote our wellbeing and the growth of civilization.

From this premise, we can argue that human beings have two morally valuable interests: (1) a general interest in natural history documentaries being produced; and (2) an interest in the reliability of the information they get from them. The first interest can directly clash against the interest of the animals in not being harmed by the making of documentaries. Below, we discuss this potential conflict and the way to balance human and animal interests. First, we focus on the second interest which can be affected by the way documentaries are made.

Generally speaking, viewers look at documentaries as a reliable source of information about animals. They trust documentaries to present true facts and they have a basic moral interest in not being deceived (and in some cases such interest is also protected by a right). Producers and film-makers have a responsibility not to deceive the viewer (Mittermeier \& Relanzon 2008). This responsibility is easy to affirm from a general point of view, but its translation into practice needs an understanding of its nature. A detailed argumentation exceeds the scope of this commentary, but we highlight some issues that such an analysis should take into account.

Even if natural history documentaries are perceived as depicting reality, in general it must be acknowledged that they do not show 'plain facts'. It is very likely that what is depicted is not free of the film-makers' opinions and values. Producers and film-makers choose the subjects of their work. They decide how and when to take the images. When the cutting is made, shots are selected and put in a chosen order. The final product is accompanied by narrative comments and often by music (in the case of video reportage). As in the case of journalistic reportage, the reality depicted in documentaries is thus always mediated. In general, it can be said that science produces theories about physical and biological laws and it aims to be objective and to discover the 'truth' about the mechanisms governing the world. But making documentaries is not a piece of science. Documentaries can relate data from science, but they are not scientific reports. They mix science, narrative, images, etc. The film-makers' point of view affects the way these are mixed. Therefore, the interest of viewers not to be deceived cannot be interpreted as the interest to see 'plain facts'. Watching a natural history documentary (like a news reportage) entails the viewer accepting the facts as seen from the film-maker's point of view. When does this mediation threaten the viewers' interest in not being deceived?

\section{Documentaries: Science, Narrative and Anthropomorphism}

Generally speaking, it could be said that the viewers' interest is protected if the information they get is in agreement with data produced by the scientific community (or, at least, if they are informed that the documentary disagrees with the currently accepted scientific point of view). When documentaries give explanations of animal behaviour in agreement with ethological research, then viewers have the chance to get the 'state of the art' of human knowledge about animal life. None the less, given the popular nature of documentaries, scientific explanations must be translated into terms understandable by lay people. Often, this translation is made using metaphors. The use of metaphors and analogies should be critically evaluated by film-makers and producers since they can misrepresent animal behaviour. For example, anthropomorphic descriptions can help viewers to understand animal behaviour but they can also be misleading. None the less, as in the case of ethological research, anthropomorphism ought not to be hastily rejected just as a methodological mistake. Critical anthropomorphism can be regarded as a heuristic device for animal behaviour research (Burghardt 1991; Guthrie 1997). If ethology can accept anthropomorphism, then natural history documentaries should too, provided that it is consciously used and critically evaluated.

There is another reason not to be too critical of anthropomorphism in the field of natural history documentaries. The educational purposes of documentaries are not limited to increasing scientific knowledge of animal life. Documentaries can also help viewers develop awareness for conservation issues. Therefore, stressing some similarities between humans and animals can help viewers sympathize with endangered species and, in general, develop a moral awareness of the animal world. But stressing resemblances between humans and animals can also be morally problematic. For example, showing some mating, sexual and parenting behaviours of animals can enforce in the public the idea that some family relationships are 'natural' and therefore morally good also for humans (Bousè 2000). Scenes of predation or fights to achieve dominance can support the idea that a 'natural' morality ought to be grounded in the survival of the fittest. This kind of misinterpretation is not necessarily deliberate, but it could be the outcome of implicit biases and prejudices of film-makers. Producers and film-makers should be aware of moral and political exploitations of biological theories and data that were made in the past.

It is impossible to give a universal formula to find a sensible use of anthropomorphism in the making of documentaries. None the less, film-makers should be aware of their potential biases and of the ethical messages implicit in the depiction of animal life. To get such awareness, professional training and education of film-makers are paramount.

\section{Animal Interests in Natural History Documentaries}

Human interest in the making of natural history documentaries (and in their reliability) is potentially in conflict with animals' interests. Generally speaking, we may recognize two basic animal interests: the interest in being alive and the interest in having good welfare. The making of an audiovisual documentary of animal life 
can threaten both (see Table 1). The nature of this conflict and the ways in which it may come about present many similarities with behavioural research. For this reason, the analysis of moral issues connected to protecting animal interests in the making of documentaries can greatly benefit from the literature on the ethics of behavioural research. None the less, there are also some relevant differences that must be stressed.

First, the differences between the human interest in the development of behavioural research and the human interest in the making of natural history documentaries must be acknowledged. Their nature is different and so is their moral weight. In general they are both linked with the flourishing of human knowledge. Behavioural research is necessary to get scientific knowledge on animal behaviour. Making a documentary is one of the means of spreading knowledge among the general public but it is not the only one. In principle, for human beings doing without documentaries should be easier than doing without behavioural research. From this premise, we can claim that interest in behavioural research seems to have, at least prima facie, a greater moral weight than interest in naturalistic documentaries. Of course, this does not mean that behavioural studies are free from ethical issues that must be taken into account by researchers. This means that risks for animal life and welfare ought to be weighed differently in behavioural research protocols and in the making of documentaries. While, in general, risks to animals' lives should be avoided or at least kept to a minimum, in the first case some risks to animal life can be morally justified, but in the second they are much less justified. There is a need for debate on whether risks to animals' lives in the making of documentaries should ever be allowed. Evaluation however, should always take into account the type of animals involved (e.g. invertebrates versus vertebrates) and their capacities (e.g. for feeling pain).

This different standard applies also to the other relevant animal interest: good welfare. Behavioural research can have negative impacts on animal welfare. There is already a huge debate about how to improve welfare in behavioural research (e.g. Huntingford 1984; Bekoff \& Jamieson 1991; Russow \& Theran 2003) and various codes and guidelines have been produced (e.g. Gaunt \& Oring 1999; Sherwin et al. 2003; Anonymous 2006; Gannon et al. 2007). In the case of documentaries, debate and analysis are much less developed, although not entirely absent.

\section{Animal Welfare and Natural History Documentaries}

Risks for animal welfare are associated with the collection of material for the production of a documentary. Approaching and recording methods can interfere with foraging and reproductive activities. Film-makers can use 'tricks' to facilitate their approach to animals or to make them display the desired behaviours. Some of these methods, although useful for the photographer/film-maker, can be more or less invasive, interfering with the lives of the animals and threatening their welfare. For example, the use of food

Table 1

Sources of risk for animal welfare in making documentaries

\begin{tabular}{llll}
\hline & Wild & Semi-captive & Captive \\
\hline Approaching and recording methods & $\mathrm{X}$ & $\mathrm{X}$ & $\mathrm{X}$ \\
Effects on the ecosystem & $\mathrm{X}$ & & $\mathrm{X}$ \\
Capture and restraining methods & & $\mathrm{X}$ & $\mathrm{X}$ \\
Use of baits and decoys & $\mathrm{X}$ & $\mathrm{X}$ & $\mathrm{X}$ \\
Use of chemical/hormonal stimulation & & $\mathrm{X}$ & $\mathrm{X}$ \\
Transport and housing conditions & & $\mathrm{X}$ & $\mathrm{X}$ \\
Training & $\mathrm{X}$ & $\mathrm{X}$ & \\
Disease transmission & $\mathrm{X}$ & $\mathrm{X}$ & \\
Human habituation & & &
\end{tabular}

as bait should be evaluated carefully, since this common means of approaching animals can seriously threaten their health. Of course, each situation presents its own kinds of risk and a classification of the various threats and their sources should take into account the different environments in which animals live: captivity, semicaptivity or wilderness (Table 1 ). Generally speaking, the greatest risks for animal welfare seem to be when animals are in captive or semicaptive conditions. These risks are counterbalanced by the fact that in captive/semicaptive conditions monitoring animals is easier and their health can be monitored and evaluated also when the process of documenting their behaviour is finished. In contrast, in the wild it is more difficult both to evaluate welfare interests of animals and to act to protect them when they are in danger.

\section{The Balance of Human and Animal Interests}

For those engaged in making documentaries, trying to avoid adverse effects on animals is paramount. However, it is impossible to eliminate all the risks for the welfare of animals, so is there a moral argument to justify those risks? Generally speaking, for humans natural history documentaries are a source of entertainment, education and information. These are important human goods and they are morally valuable. So, at first sight, satisfaction of human interests can balance some risk for animal interests, but case by case evaluations are needed to understand the actual interests and to produce morally sound courses of action. Some fixed and general rules can build a framework for such case by case judgements. For example, voluntarily causing the death of an animal to make a film seems to be unacceptable in every case, whatever human interests would be satisfied. These general rules can be coded in guidelines and codes of conduct for professionals working in the field and in national and international legislations (see below for an overview of some existing guidelines). Anyway, since codes and law cannot cover all the possible situations, case by case evaluations should always be made by those who actually make the documentaries.

\section{Protecting Animals in Documentaries: Norms and Policies}

The welfare of animals subjected to audiovisual recording is protected by laws, codes and guidelines regulating human-animal relations in general. For example, laws protecting wild fauna and regulating human activities in restricted areas, of course, apply also to photographers and film-makers (e.g. Council of Europe 1979). Laws and codes regulating film making in general are also applicable (e.g. Cinematograph Films (Animals) Act 1937; British Board of Film Censors 2005). At present, the most accurate norms specifically aimed at regulating the making of documentaries are not issued by governments, but by corporations, scientific societies or associations of professionals (e.g. Scandinature Films 1997; North American Nature Photography Association 2003). The development of international shared guidelines and norms would represent an important step towards improving of animal welfare also in the context of documentary production.

Norms and guidelines cannot by themselves guarantee the protection of animal welfare in the making of documentaries. Such protection depends mostly on the skills of professionals in evaluating situations case by case and acting adequately and responsibly. To get and to improve their capacities and to understand their own responsibilities, professionals need education and information. Photographers and film-makers are free to get or not the education needed to face the moral issues of their work. It is open to debate whether it should be compulsory for professionals to have a basic training in animal behaviour and welfare science to get an international licence qualifying them to take photos of and video record 
animals. A licensing scheme for professionals of naturalistic documentaries could be introduced, at least for taking photos of, and video recording, endangered species. Film crews could also be required, at least in the riskiest situations, to include as consultants a veterinarian expert in animal welfare and/or an ethologist trained in conservation issues. Of course, to avoid conflicts among the codes of conduct and regulations to which the various professionals are subjected, actions to harmonize them will be required. Additional requirements could oblige film-makers to keep confidential any information that could threaten animal life and welfare if it were spread (e.g. the location of nesting sites).

\section{Conclusions}

Human beings have morally sound interests in recording and viewing animal behaviour. On the other hand, animals have interests in not being harmed in the making of reportage and documentaries. At first sight, it seems that avoiding harm could be enough to guarantee a morally acceptable balance of interests of humans and animals. Humans get the satisfaction of their interests in knowledge and entertainment, while animals keep their lives and welfare untouched. Animals can also benefit, but in a different way from humans. Natural history documentaries are important for promoting sensibility and awareness of conservation issues. However, it seems unlikely that the animals involved in the production of a documentary would themselves benefit. Also, the changes in perception that are likely to result from documentaries may happen over long periods of time and changes in personal habits will not necessarily be translated into public policies in favour of animals. Therefore it seems that, by themselves, they cannot constitute a fair reward for animals.

Animals could also benefit by some form of compensation. For example, some kind of taxation on the making of documentaries could be established to be spent for conservation projects. Means to put this taxation in practice could be various. For example, it could be imposed on the royalties derived from the exercise of filmmakers' rights in the selling and licensing of documentaries.

At present, measures such as taxation would be very difficult to achieve in the short term. A more realistic goal would be to start a process of elaboration of international guidelines shared among the different professionals involved in the making of documentaries. To start this process, public debate and discussion of ideas are essential.

We are grateful to Patrizia Messeri, Cristina Mittermeier and Chris Palmer for their very useful comments on this paper. We thank Martin Plath for his comments, especially on terminology, that help clarify the text and a second anonymous referee for his constructive review. This work was supported by the grant 451/759 of the Italian National Research Council (CNR).

\section{References}

Anonymous 2006. Guidelines for the treatment of animals in behavioural research and teaching. Animal Behaviour, 71, 245-253, doi:10.1016/j.anbehav.2005. 10.001.

Bekoff, M. \& Jamieson, D. 1991. Reflective ethology, applied philosophy, and the moral status of animals. Perspectives in Ethology, 9, 1-47.

Bousè, D. 2000. Wildlife Films. Philadelphia: University of Pennsylvania Press.

British Board of Film Censors. 2005. Guidelines. http://www.bbfc.co.uk/policy/ index.php Read: 8 February 2009.

Burghardt, G. M. 1991. Cognitive ethology and critical anthropomorphism: a snake with two heads and hognose snakes that play dead. In: Cognitive Ethology: The Minds of Other Animals: Essays in Honor of Donald R. Griffin (Ed. by C. A. Ristau), pp. 53-90. Hillsdale, New Jersey: L. Erlbaum.

Films (Animals) Act, Cinematograph. 1937. http://www.legislation.gov.uk/ RevisedStatutes/Acts/ukpga/1937/cukpga_19370059_en_1 Read: 8 February 2009.

Council of Europe. 1979. Convention on the conservation of European wildlife and natural habitats, Bern. http://conventions.coe.int/treaty/on/treaties/html/104. htm Read: 8 February 2009.

Fraser, D. 1999. Animal ethics and animal welfare science: bridging the two cultures. Applied Animal Behaviour Science, 65, 171-189.

Gannon, W. L. \& Sikes, R. S., The Animal Care and Use Committee of the American Society of Mammalogists 2007. Guidelines of the American society of mammalogists for the use of wild mammals in research. Journal of Mammalogy, 88, 809-823.

Gaunt, A. S. \& Oring, L. W. 1999. Guidelines to the Use of Wild Birds in Research, 2nd edn. Washington, O.C.: The Ornithological Council. http://www.nmnh.si.edu/ BIRDNER/GoudeTollse Read: 8 February 2009.

Guthrie, S. E. 1997. Anthropomorphism: a definition and a theory. In: Anthropomorphism, Anecdotes and Animals (Ed. by R. W. Mitchell, N. S. Thompson \& H. L. Miles), pp. 50-58. Albany, New York: State University of New York Press.

Huntingford, F. A. 1984. Some ethical issues raised by studies of predation and aggression. Animal Behaviour, 32, 210-215.

Mittermeier, C. \& Relanzon, I. 2008. Disclosure and truthfulness in conservation photography, a photojournalism moral compass. http://www.naturescapes.net/ docs/index.php/articles/340 Read: 8 February 2009.

North American Nature Photography Association. 2003. Principles of ethical field practices. http://www.nanpa.org/docs/principles.pdf Read: 8 February 2009

Russow, L. M. \& Theran, P. 2003. Ethical issues concerning animal research outside the laboratory. ILAR Journal, 44, 187-190.

Scandinature Films. 1997. Guidelines for filming and handling animals. http:// www.muddyboots.se/index.asp?id=449 Read: 8 February 2007.

Sherwin, C., Christiansen, S. B., Duncan, I. J., Erhard, H. W., Lay Jr., D. C. Mench, J. A., O'Connor, C. E. \& Petherick, J. C. 2003. Guidelines for the ethical use of animals in applied ethology studies. Applied Animal Behaviour Science, 81, 291-305, doi:10.1016/S0168-1591(02)00288-5.

Tosi, V. 1984. Il Cinema Prima di Lumiere. Torino: Edizioni Rai Radio Televisione Italiana. 